\title{
Influence Of The Paired Under-Passing Training Model On The Under-Passing Ability Of Volleyball Players
}

\author{
AndikaWulandari Pasaribu ${ }^{1}$, ArieAsnaldi ${ }^{2}$ \\ Program Studi Pendidikan Jasmani Kesehatan dan Rekreasi, Universitas Negeri Padang, Indonesia \\ Email Korespoden: wulandari123@gmail.com ${ }^{1}$, asnaldi@fik.unp.ac.id ${ }^{2}$
}

\begin{abstract}
The purpose of this study is to find out the influence of the lower pairing passing training model on the ability to pass under the volleyball players of SMP Negeri 24 North Bengkulu. This type of research is a quasi-experiment that aims to look at the influence of the lower paired passing exercise model on the ability to pass under the volleyball. The population in this study was all volleyball players of SMP Negeri 24 Bengkulu Utara as many as 21 people. Sampling was conducted with purposive sampling techniques that are men's players as many as 12 people. To get the research data users the ability to pass under volleyball from the wall volleyball test. Data obtained in the analysis with the t-test. Based on the results of the data analysis it is known that the model of the lower passing exercise in pairs exerts a meaningful influence on the ability to pass down the volleyball. Where the test is obtained different mean (t-test) of t-count 14,409 while t-table is 2,201 with significant level $\alpha=$ 0.05 and $\mathrm{n}=12$, then $\mathrm{t}$-count $>\mathrm{t}$-table $(14,409>2,201)$, so it can be concluded that there is a significant influence of the lower pairing passing training model on the lower passing ability of the volleyball players of SMP Negeri 24 North Bengkulu.
\end{abstract}

Keywords: Lower Passing Pairs, Lower Passing Ability

\begin{abstract}
Abstrak
Tujuan dari penelitian ini adalah untuk mengetahui pengaruh model latihan passing bawah berpasangan terhadap kemampuan passing bawah pemain bolavoli SMP Negeri 24 Bengkulu Utara. Jenis penelitian ini adalah eksperimen semu (quasi eksperimen) yang bertujuan untuk melihat pengaruh model latihan passing bawah berpasangan terhadap kemampuan passing bawah bolavoli. Populasi dalam penelitian ini adalah seluruh pemain bolavoli SMP Negeri 24 Bengkulu Utara sebanyak 21 orang. Pengambilan sampel dilakukan dengan teknik purposive sampling yaitu pemain putra sebanyak 12 orang. Untuk mendapatkan data penelitian digunakan tes kemampuan passing bawah bolavoli dari braddy wall volleyball test. Data yang diperoleh dianalisis dengan uji t. Berdasarkan hasil analisis data diketahui bahwa model latihan passing bawah berpasangan memberikan pengaruh yang berarti terhadap kemampuan passing bawah bolavoli. Dimana diperoleh uji beda mean (uji t) sebesart $t_{\text {hitung }} 14,409$ sedangkan $t_{\text {tabel }}$ sebesar 2,201 dengan taraf signifikan $\alpha=0,05$ dan $\mathrm{n}=12$, maka $\mathrm{t}_{\text {hitung }}>\mathrm{t}_{\text {tabel }}(14,409>2,201)$, jadi dapat disimpulkan bahwa adanya pengaruh yang signifikan dari model latihan passing bawah berpasangan terhadap kemampuan passing bawah pemain bolavoli SMP Negeri 24 Bengkulu Utara.
\end{abstract}

Kata Kunci :Passing Bawah Berpasangan, Kemampuan Passing Bawah

\section{PENDAHULUAN}

Permainan bolavoli tidak sekedar dilakukan hanya untuk tujuan rekreasi dan mengisi waktu luang saja, tetapi untuk pencapaian suatu prestasi yang optimal. Untuk mencapai prestasi yang optimal diperlukan suatu latihan yang terprogram dengan baik. Pada saat ini banyak hal yang perlu diperhatikan oleh pelatih maupun atlet itu sendiri misalnya penguasaan teknik, taktik, mental, kondisi fisik dan model latihan yang mendukung untuk peningkatan prestasi maupun kemampuan dalam bertanding. Menurut Syahrir (2018:4) (Asnaldi et al., 2020)"Permainan bolavoli sangat ditentukan oleh penguasaan teknik, taktik kerja sama tim dan unsur kondisi fisik pemain. Kualitas permainan 
Influence Of The Paired Under-Passing Training Model On The Under-Passing Ability Of

Volleyball Players

AndikaWulandari Pasaribu ${ }^{1}$, ArieAsnaldi ${ }^{2}$

sangat ditentukan oleh kesempurnaan penguasaan teknik dasar, semakin sempurna penguasaan teknik dasar semakin berkualitas permainan yang ditampilkan. Adapun teknik dasar dalam permainan bolavolia dalah Service, Passing, Smash, Blocking”.

Berdasarkan pendapat di atas penulis menyimpulkan bahwa dalam bermainan bolavoli sangat diperlukan penguasaan teknik yang terdiri dari Service, Passing, Smash, Blocking, taktik kerjasama tim dan kondisi fisik pemain. Menurut Erianti (2004:109)(Asnaldi, 2020a), "dalam usaha meningkatkan prestasi pemain, khususnya pemain bolavoli, perlu ditingkatkan unsur-unsur kondisi fisik, teknik, taktik, kematangan mental, kerjasama, dan kekompakan serta pengalaman dari bertanding". Kerjasama ketujuh faktor ini menentukan prestasi atau kemampuan dalam pertandingan.

Berdasarkan pendapat di atas ternyata banyak faktor penunjang untuk pencapaian prestasi, dengan ketujuh komponen menunjang prestasi tersebut maka seharusnya prestasi pemain hendaknya dapat meningkat. Namun kenyataannya masih banyak di antara para pemain yang memiliki kemampuan teknik yang rendah, sehingga dapat menyebabkan menurunnya prestasi pemain.

Peneliti melakukan pengamatan dan observasi pada pemain bolavoli SMP Negeri 24 Bengkulu Utara pada tanggal 15 november 2019. Kemudian peneliti dapati dalam satu sesi latihan dan pertandingan tim sering mengalami kegagalan dalam melakukan serangan dan menerima serangan lawan. Selain itu masih ada dari pemain yang tergabung dalam tim secara nyata melakukan kesalahankesalahan teknik dalam latihan atau bermain.

Adapun kesalahan-kesalahan yang dimaksud adalah pemain tidak bisa menerima bola dari serangan lawan dengan baik, pada saat menghadapi bola serangan kaki kurang ditekuk atau tidak pada posisi setengah jongkok sehingga bola tidak terarah dan menyebabkan bola keluar dari lapangan. Hasil passing bawah tidak sampai keteman berpengaruh pada penerimaan bola menjadi tidak terkontrol, mengakibatkan toser mengalami kesulitan untuk melakukan umpan smash.(Asnaldi, 2020b)

Kemampuan menerima dan mengontrol datangnya bola dalam permainan bolavoli, anggota tubuh yang berperan adalah otot lengan karena apabila kekuatan otot lengan yang dimiliki oleh pemain mampu menahan serangan bola di berbagai kondisi dalam permainan, maka pemain dapat dengan mudah menahan serangan lawan, pemain juga dapat menempatkan bola secara tepat pada sasaran. Selain itu latihan teknik juga menjadi faktor utama yang harus di latih agar pemain dapat melakukan passing dengan baik dan benar(Asnaldi, 2020a)(Johor et al., 2020).

Kesalahan-kesalahan yang terjadi lainnya pada pemain yaitu pemain kesulitan menggambil bola ke kiri atau ke kanan ketika menerima servis maupun smash. Selain itu beberapa pemain tidak begitu cepat menggerakan anggota tubuhnya pada saat penyelamatan bola(Asnaldi et al., 2020). Setelah melakukan pengamatan, masih banyak pemain yang kemampuan dalam passing bawah masih belum sempurna, karena masih kurangnya variasi latihan passing bawah sehingga passing bawah pemain masih kurang maksimal.

Untuk memecahkan permasalahan ini penulis berkeinginan dan mengusulkan kepada pelatih bolavoli SMPNegeri 24 Bengkulu Utara, sebuah program latihan bentuk pengembangan materi-materi model latihan passing bawah berpasangan. Dengan bentuk latihan ini kemungkinan pemain bolavoli SMP Negeri 24 Bengkulu Utara akan lebih tertarik dan termotivasi dalam latihan. Kemudian pemain akan memperoleh sesuatau yang baru, menyenangkan, dan mampu membuat pemain bergerak aktif dalam latihan bolavoli. Sehingga diharapkan akan memberikan dampak positif bagi pemain untuk giat dalam melakukan latihan passing bawah agar dapat meningkatkan prestasi bolavoli.

Adapun materi model latihan passing bawah berpasangan yang penulis usulkan adalah latihan passing bawah berpasangan dengan rotasi kebelakang, latihan passing bawah rotasi kearah larinya bola dan latihan passing bawah tanpa melewati garis batas.

Mukholid dalam Syahrir (2018:5) mengatakan bahwa:

"Permainan bolavoli adalah suatu permainan yang menggunakan bola untuk dipantulkan (divolley) di udara hilir mudik di atas net (jaring), dengan maksud dapat menjatuhkan bola di dalam petak daerah lapangan lawan dalam rangka mencari kemenangan. Mem-volley atau melambungkan bola keudara dapat mempergunakan seluruh anggota atau bagian tubuh dari ujung kaki sampai ke kepala dengan pantulan sempurna".

Untuk dapat menguasai teknik dasar passing bawah, M. Yunus dalam Herman (2019:37) mengemukakan beberapa hal sebagai berikut:

1. Sikap Permulaan

\section{Edisi Oktober}


Kedua lutut ditekuk dengan badan sedikit dibengkokkan ke depan, berat badan menumpu pada telapak kaki bagian depan untuk mendapatkan suatu keseimbangan labil agar dapat lebih mudah dan lebih cepat bergerak kesegala arah. Kedua tangan saling berpegangan yaitu : punggung tangan kanan diletakkan di atas telapak tangan kiri kemudian saling berpegangan.
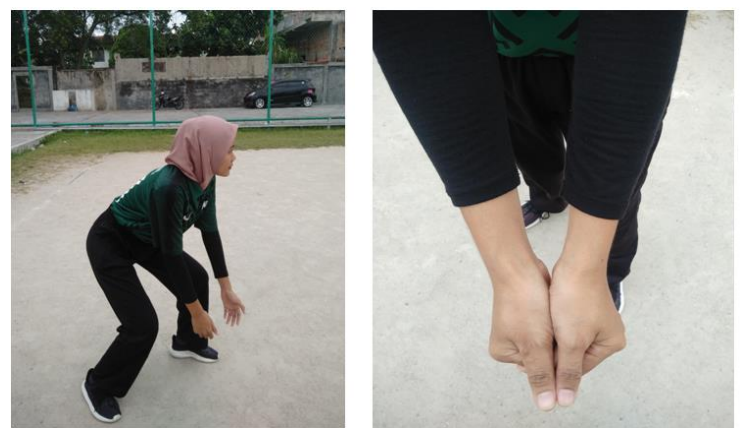

\section{Gambar 1. Sikap Permulaan Passing Bawah} Sumber: Dokumentasi Peneliti

\section{Gerak Pelaksanaan}

Ayunkan kedua lengan ke arah bola, dengan sumbu gerak pada persendian bahu dan siku betul-betul dalam keadaan lurus. Perkenaan bola pada bagian prosimal dari lengan, di atas dari pergelangan tangan dan pada waktu lengan membentuk sudut sekitar 45 derajat dengan badan, lengan diayunkan dan diangkat hampir lurus.
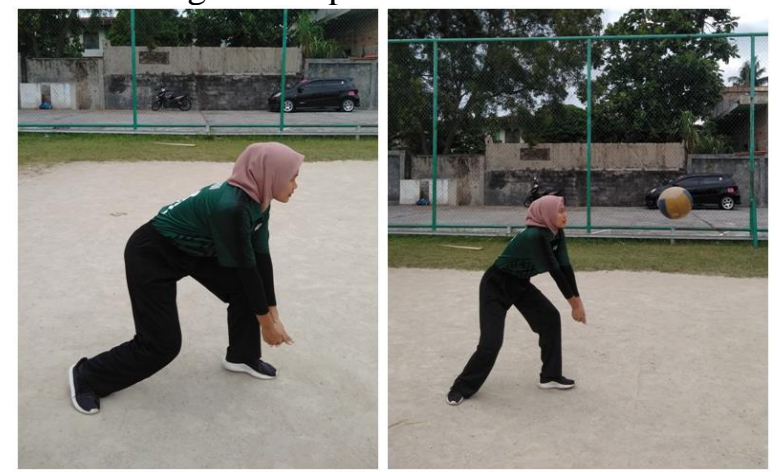

Gambar 2. Gerak Pelaksanaan Passing Bawah Sumber: Dokumentasi Peneliti

\section{Gerak Lanjutan}

Setelah ayunan lengan mengenai bola, kaki belakang melangkah kedepan untuk mengambil sikap kembali. Ayunan lengan untuk passing bawah kedepan tidak melebihi sudut 90 derajat dengan bahu dan badan.

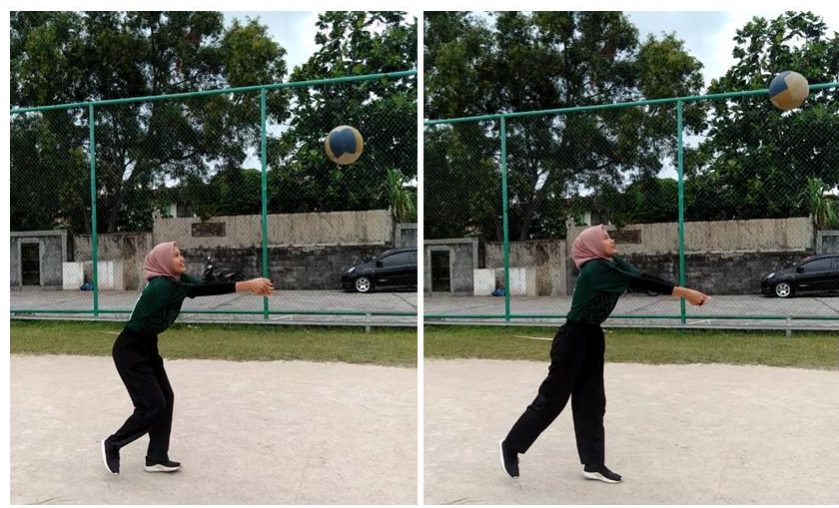

Gambar 3. Gerak Lanjutan Passing Bawah Sumber: Dokumentasi Peneliti 
Influence Of The Paired Under-Passing Training Model On The Under-Passing Ability Of

Volleyball Players

AndikaWulandari Pasaribu ${ }^{1}$, ArieAsnaldi ${ }^{2}$

Otot lengan yang berperan ketika melakukan passing bawah adalah otot biceps. Menurut Umar (2014:91) "Otot biceps berfungsi untuk menggerakan lengan bawah (flexcio) pada sendi siku. Gerakan dalam olahraga banyak ditemukan penggunaannya pada cabang angkat besi/angkat berat seperti arm curl, pass bawah pada bolavoli dan lain-lain". Djoko Pekik Irianto dalam Nurul Hadiyani (2013:22) mengatakan "Latihan yang baik dilakukan secara bertahap agar memperoleh hasil yang optimal. Tahapan latihan yaitu pendahuluan, pemanasan, latihan inti, dan penenangan". Setiap tahapan latihan mempunyai manfaat dan tujuan masing-masing. Pendahuluan dilakukan untuk mempersiapkan diri dengan latihan yang akan dilakukan.

\section{METODE}

Jenis penelitian yang digunakan dalam penelitian ini adalah jenis eksperimen semu. Eksperimen semu merupakan penelitian yang mendekati percobaan sungguhan dimana tidak mungkin mengadakan kontrol atau memanipulasikan semua variabel yang relevan. Eksperimen semu bertujuan untuk mengungkapkan hubungan sebab akibat dengan cara melibatkan kelompok kontrol disamping kelompok eksperimen. Namun, pemilihan kedua kelompok tersebut tidak dengan teknik random dan untuk menjelaskan hubungan-hubungan, mengklarifikasi penyebab terjadinya suatu peristiwa. Arikunto (2010:9).

Penelitian ini dilakukan di SMP Negeri 24 Bengkulu Utara yang dilaksanakan pada bulan Agustus - September 2020. Populasi dalam penelitian ini adalah seluruh pemain bolavoli SMPN 24 Bengkulu Utara sebanyak 21 orang dengan rincian 12 orang putra dan 9 orang putri. Sampel dalam penelitian ini ditetapkan hanya pemain bolavoli putra SMP Negeri 24 Bengkulu Utara sebanyak 12 orang. Data yang diperlukan dalam penelitian ini adalah hasil kemampuan Passing bawah yang dilakukan siswa pada tes awal dan tes akhir dimana semua ini dilakukan peneliti bersama dengan prosedur penelitian yang telah dituliskan sehingga akan mendapatkan data primer yang baik.

Dalam penelitian ini instrument tes menggunakan Braddy Volley Ball Test yang sudah dimodifikasi oleh Kirana dalam Fanny Ardiansyah (2016:30). Sebelum dilakukan analisis uji t terlebih dahulu dilakukan uji normalitas. Setelah uji normalitas dilakukan, maka dilakukan analisis uji t-tes.

\section{HASIL DAN PEMBAHASAN}

Hasil Penelitian

Hasil penelitian digambarkan sesuai dengan tujuan dan hipotesis yang diajukan sebelumnya.

\section{Pre Test Kemampuan Passing Bawah}

Pengukuran pre testkemampuan passing bawahdilakukan sebelum di berikan perlakuan, yaitu model latihan passing bawah berpasangankepada sampel 12 pemain bolavoli SMP Negeri 24 Bengkulu Utara. Dari hasil pengukuran pre testkemampuan passing bawahtersebut di dapat, yaitunilai minimal 17 kali dan nilai maksimal 31 kali. Kemudian diperoleh juga mean sebesar 24,25 kali dan standar deviasi sebesar 4,6539 kali.

Untuk mengetahui sebaran data lengkap dari pre testkemampuan passing bawah dapat dilihat pada tabel berikut:

Tabel 5. Distribusi Frekuensi Pre TestKemampuan Passing Bawah

\begin{tabular}{|c|c|c|c|}
\hline \multirow{2}{*}{ No } & \multirow{2}{*}{ Kelas Interval } & \multicolumn{2}{|c|}{ Pre Test } \\
\cline { 3 - 4 } & & Absolut (Fa) & Relatif (\%) \\
\hline 1 & $>31,27$ & 0 & $0,00 \%$ \\
\hline 2 & $26,62-31,22$ & 4 & $33,33 \%$ \\
\hline 3 & $21,93-26,57$ & 4 & $33,33 \%$ \\
\hline 4 & $17,28-21,88$ & 3 & $25,00 \%$ \\
\hline 5 & $<17,23$ & 1 & $8,33 \%$ \\
\hline & Jumlah & $\mathbf{1 2}$ & $\mathbf{1 0 0 , 0 \%}$ \\
\hline
\end{tabular}

\section{Edisi Oktober}




\section{Edisi Oktober}

Volume 4, Nomor 2,2020 ( $57-64$ )

Doi: https://doi.org/10.34004/jurgupenprof.422020.06 berikut ini:

Untuk lebih jelasnya data pre test kemampuan passing bawah dapat dilihat pada histogram

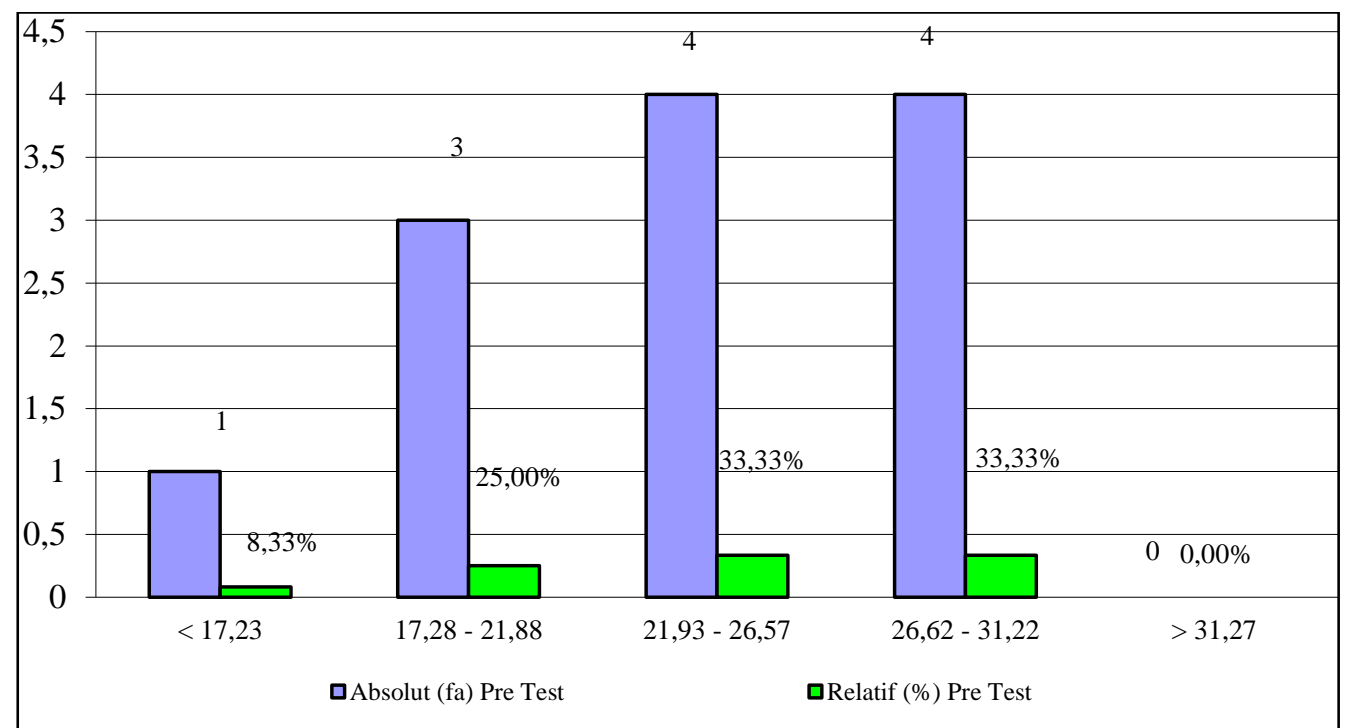

Gambar 12. Histogram Batang Pre TestKemampuan Passing Bawah

\section{Post TestKemampuan Passing Bawah}

Pengukuran post testkemampuan passing bawah dilakukansetelah mendapatkan perlakuan, yaitu model latihan passing bawah berpasanganselama 16 kali pertemuan kepada sampel 12 pemain bolavoli SMP Negeri 24 Bengkulu Utara. Dari hasil pengukuran post testkemampuan passing bawahtersebut di dapat, yaitunilai minimal 26 kali dan nilai maksimal 36 kali. Kemudian diperoleh juga mean sebesar 31,08 kali dan standar deviasi sebesar 3,6045 kali.

Untuk mengetahui sebaran data lengkap dari post testkemampuan passing bawah dapat dilihat pada tabel berikut:

Tabel 6. Distribusi Frekuensi Post TestKemampuan Passing Bawah

\begin{tabular}{|c|c|c|c|}
\hline \multirow{2}{*}{ No } & \multirow{2}{*}{ Kelas Interval } & \multicolumn{2}{|c|}{ Post Test } \\
\cline { 2 - 4 } & & Absolut (Fa) & Relatif (\%) \\
\hline 1 & $>31,27$ & 6 & $50,00 \%$ \\
\hline 2 & $26,62-31,22$ & 4 & $33,33 \%$ \\
\hline 3 & $21,93-26,57$ & 2 & $16,67 \%$ \\
\hline 4 & $17,28-21,88$ & 0 & $0,00 \%$ \\
\hline 5 & $<17,23$ & 0 & $0,00 \%$ \\
\hline & Jumlah & $\mathbf{1 2}$ & $\mathbf{1 0 0 , 0 \%}$ \\
\hline
\end{tabular}

berikut ini:

Untuk lebih jelasnya data post test kemampuan passing bawah dapat dilihat pada histogram 


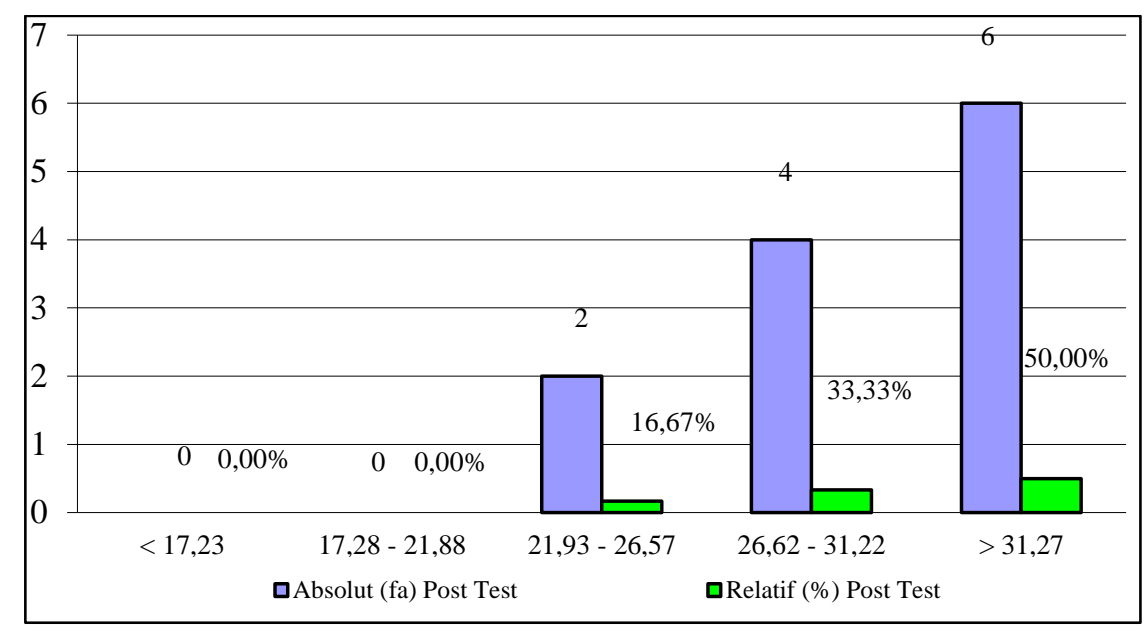

Gambar 13. Histogram Batang Post TestKemampuan Passing Bawah

\section{Pembahasan}

Berdasarkan hasil penelitian yang dilakukan dilapangan, membuktikan bahwa terdapat pengaruh model latihan passing bawah berpasangan terhadap kemampuan passing bawah pemain bolavoli SMP Negeri 24 Bengkulu Utara. Sebelum diberikan perlakuan terhadap sampel, terlebih dahulu diketahui kemampuan maksimal passing bawah pemain, denga nmelakukan tes awal. Berdasarkan hasil tes tersebut ternyata kemampuan passing bawah diperoleh rata-rata pada saat pretest yaitu sebesar 24,25 kali. Namun setelah diberikan perlakuan dengan model latihan passing bawah berpasangan maka terjadi peningkatan dengan rata-rata menjadi 31,08 kali.

Hal ini diperkuat setelah dilakukan uji t, dimana diperoleh hasil $t_{\text {hitung }}$ sebesar 14,409 yang lebih besar dari tabel dalam taraf $\alpha=0.05$ sebesar 2,201. Dengan hasil penelitian ini berarti hipotesis yang diajukan dalam dapat diterima kebenarannya, dalam kalimat lain dapat disimpulkan bahwa model latihan passing bawah berpasangan memberikan pengaruh yang signifikan terhadap kemampuan passing bawah pemain bolavoli SMP Negeri 24 Bengkulu Utara.

Langkah awal yang peneliti lakukan dalam penelitian ini yaitu melaksanakan ujian seminar proposal dan mengurus surat izin penelitian. Selanjutnya untuk mendapatkan data dalam penelitian ini peneliti melaksanakan tes awal (pre test) dengan menggunakan instrumen Braddy Volley Ball Test yang sudah dimodifikasi oleh Kirana dalam Fanny Ardiansyah (2016:30), dengan menurunkan daerah sasarannya sesuai dengan tinggi anak SMP yaitu dari yang semula tinggi jarak sasaran dari lantai 3,5 meter diturunkan menjadi 2,5 meter, sedangkan lebar daerah sasaran tetap $152 \mathrm{~cm}$. Tinggi sasaran yang digunakan adalah 2,5 meter karena selain tinggi tersebut sudah melebihi tinggi net dan dengan ketinggian tersebut diharapkan siswa akan lebih mudah menguasai dan mengontrol bola. Tes ini di desain untuk siswa SMP yang sudah dimodifikasi dengan tujuan untuk mengukur ketrampilan umum dalam bermain bolavoli dengan cara memvoli bola berulang-ulang ke arah sasaran selama 1 menit dengan dua kali pengulangan. Nilai akhir diambil dari salah satu nilai maksimal dari dua kali pengulangan tes tersebut. Hasil dari tes awal tersebut di dapat nilai minimal 17 kali dan maksimal 31 kali.

Setelah mendapatkan hasil dari tes awal, selanjutnya peneliti memberikan perlakuan berupa program latihan dari model latihan passing bawah berpasangan. Adapun materi dari model latihan passing bawah berpasangan adalah latihan passing bawah berpasangan dengan rotasi ke belakang, latihan passing bawah berpasangan dengan rotasi ke arah larinya bola, dan latihan passing bawah tanpa melewati garis batas. Program latihan ini dilaksanakan selama 16 kali pertemuan dengan jadwal latihan setiap hari senin, rabu dan jumat. Latihan tersebut dimulai dari jam 16.00 sampai selesai.

Selanjutnya setelah selesai memberikan perlakuan, peneliti melakukan tes akhir (post test) kepada pemain menggunakan instrumen Braddy Volley Ball Test yang sudah dimodifikasi. Hasil dari tes tersebut terjadi peningkatan dengan didapat nilai minimal 26 kali dan maksimal 36 kali.

Tapi tidak terlepas dari hasil yang diperoleh pada penelitian ini, faktor-faktor yang berkaitan dengan proses latihan juga sangat mempengaruhi hasil yang di capai, seperti intensitas, durasi, volume, frekuensi dan interval dalam latihan itu sendiri. Karena masing-masing faktor tersebut turut 
berperan terhadap kelangsungan latihan yang terprogram.

\section{SIMPULAN DAN SARAN}

Berdasarkan hasil penelitian dan pengujian hipotesis maka dapat ditarik kesimpulan bahwa adanya pengaruh yang signifikan dari model latihan passing bawah berpasangan terhadap kemampuan passing bawah pemain bolavoli SMP Negeri 24 Bengkulu Utara. Setelah dilakukan uji beda mean (uji t), dimana diperoleh hasil $t_{\text {hitung }}$ sebesar 14,409 sedangkan $t_{\text {tabel }}$ sebesar 2,201 dengan taraf signifikan $\alpha$ $=0,05$ dan $\mathrm{n}=12$, maka $t_{\text {hitung }}$ lebih besar dari $t_{\text {tabel }}(14,409>2,201)$.

Berdasarkan pada kesimpulan di atas, maka penulis memberikan beberapa saran agar dapat membantu mengatasi masalah yang ditemui dalam peningkatan kemampuan passing bawah pemain bolavoliSMP Negeri 24 Bengkulu Utara, yaitu:

1. Bagi pelatih bolavoli SMP Negeri 24 Bengkulu Utara untuk dapat menggunakan model latihan passing bawah berpasangan dalam meningkatkan kemampuan passing bawah pemain bolavoli.

2. Bagi pemain bolavoli SMP Negeri 24 Bengkulu Utara perlunya memperhatikan dan menyadari bahwa model latihan passing bawah berpasangan dapat meningkatkan kemampuan passing bawah, agar termotivasi dan lebih semangat dalam berlatih.

3. Bagi pihak sekolah SMP Negeri 24 Bengkulu Utara diharapkan dapat memberikan perhatian dan dukungan kegiatan pertandingan antar sekolah yang diadakan, hal ini dapat mengharumkan nama sekolah karena siswa dapat berprestasi dalam cabang olahraga dan menjadi utusan dari kabupatennya ke tingkat propinsi.

4. Peneliti selanjutnya agar dapat melakukan penelitian dengan kajian yang sama dengan waktu yang lebih lama, sehingga pengontrolan terhadap sampel lebih banyak. Sehingga hal ini lebih dapat dilihat pengaruhnya dalam meningkatkan kemampuan passing bawah pemain bolavoli.

\section{DAFTAR RUJUKAN}

ArikuntoSuharsimi. 2010. ProsedurPenelitian. Jakarta : PT Rinikecipta.

Asnaldi, A. (2020a). Hubungan Kelentukan dan Daya Ledak Otot Lengan Terhadap Ketepatan Smash Bolavoli. Physical Activity Journal, 1(2), 160-175.

https://doi.org/https://doi.org/10.32424/1.paju.2020.1.2.2556

Asnaldi, A. (2020b). Hubungan Daya Tahan Aerobik Dan Daya Tahan Kekuatan Otot Lengan Dengan Kemampuan Smash Pemain Bulutangkis. Jurnal MAENPO: Jurnal Pendidikan Jasmani Kesehatan Dan Rekreasi, 10(1), 36-43. https://jurnal.unsur.ac.id/maenpo/article/view/940

Asnaldi, A., Yelis, R., Zulman, Atradinal, Putri, L. P., \& Bakhtiar, S. (2020). The Differences of Ability in the Level of Development on Control Objects of Early Childhood Education Students in Pariaman City and Padang Panjang City. Proceedings of the 1st International Conference of Physical Education (ICPE 2019), 97-100. https://doi.org/10.2991/assehr.k.200805.028

Johor, Z., Candra, R., Rasyid, W., Asnaldi, A., Oktarifaldi, \& Bakhtiar, S. (2020). Effect of Hand-Eye Coordination on the Capability of Children Object Control. Proceedings of the 1st International Conference of Physical Education (ICPE 2019), 204-207. https://doi.org/10.2991/assehr.k.200805.056

Erianti. 2004. BukuAjar Bola Voli. Padang: FIK UNP

Firmansyah, A. S. 2017. AnalisisKondisiFisik Tim Bolavoli Putra Unesa. JurnalPrestasiOlahraga, $1(1)$.

Herman, H. 2019. Kontribusi Kondisi Fisik Terhadap Kemampuan Passing Bawah Dalam 
Influence Of The Paired Under-Passing Training Model On The Under-Passing Ability Of

Volleyball Players AndikaWulandari Pasaribu ${ }^{1}$, ArieAsnaldi ${ }^{2}$

Permainan Bolavoli Pada Siswa MAN 2 Kota Makassar. Exercise: Journal of Physical Education and Sport, 1 (1), 34-48.

Fanny Ardiansyah. 2016. Tingkat Keterampilan Bermain Bolavoli Siswa Putra Kelas VIII Tahun Pelajaran 2015/1016 Di SMP Negeri 1 Puring Kabupaten Kebumen- Jawa Tengah. Jurusan Pendidikan Olahraga, Fakultas Ilmu Keolahragaan, Universitas NegeriYogyakarta,

SKRIPSI.http://eprints.uny.ac.id/39225/1/FANNY\%20ARDIANSYAH\%20\%2809 601244035\%29\%20SKRIPSI.pdf

Sugiyono. 2012. MetodePenelitianPendidikanPendekatanKuantitatif, Kualitatif, Dan $R \quad \& \quad D$. Bandung: Alfabeta.

Syahrir, S., Suwardi, S., \&Jayadi, W. 2018.PengaruhDayaLedakLengan, DayaLedakTungkaidanKoordinasi Mata TanganterhadapKemampuan Passing BawahdalamPermainanBolavoliSiswa SMA Negeri 1 Takalar (Doctoral dissertation, UNIVERSITAS NEGERI MAKASSAR).

Umar. 2014. AnatomiTubuhManusia. Padang: FIK UNP. 